\title{
Simultaneous saline irrigation during retrograde rigid ureteroscopic lasertripsy for the prevention of proximal calculus migration
}

\author{
Lu Sun; Fang-li Peng ${ }^{\dagger}$ \\ *Department of Urology, The People's Hospital of Yichun, Yichun, Jiang Xi, China; 'Aesthetic Medical School, Yichun University, Yichun, Jiang Xi, China
}

Cite as: Can Urol Assoc J 2013;7 (2):E65-E68. http://dx.doi.org/10.5489/cuai.226

\section{Abstract}

Objective: In this paper, we analyze the clinical efficacy of a simultaneous saline irrigation method in treating upper-mid ureteral stone migration and evaluate its effectiveness during ureteroscopic lasertripsy.

Methods: We prospectively evaluated 78 patients with a total of 95 upper-mid ureteral stones, which were treated with holmium:YAG lasertripsy. These patients were randomized into 2 groups. In Group 1 (39 cases with 44 ureteral stones), conventional ureteroscopic lasertripsy was performed. In Group 2, (39 cases with 51 ureteral stones), the simultaneous saline irrigation method was used during lasertripsy. There was no significant difference between the groups with regards to stone site, size or state of the upper urinary tract by spiral computed tomography or excretory urography. Data were analyzed regarding stone migration, lengths of time, and ureteral clearing for various stages of each procedure.

Results: One patient in Group 2 (2\%) experienced upward stone migration, while this occurred in 8 patients in Group 1 (20\%). The operative time in Group 1 ranged from 35 to 55 minutes (mean: $44.8 \pm 5.3$ ), while in Group 2 it ranged from 40 to 69 minutes (mean: $50.4 \pm 3$ ). There was no significant different in the operative times between the two groups $(p<0.05)$. Ureteral perforation, urinoma and urosepsis were not seen in both groups.

Conclusion: The simultaneous saline irrigation method demonstrated a statistically significant advantage over conventional methods. The operation can be performed persistently under clear vision, and since the stones cannot move upward, fragmented portions are easily flushed out. Our data suggest that this method is simple, safe and effective in preventing proximal stone migration during ureteroscopic lasertripsy.

\section{Introduction}

The management of ureteral calculi has dramatically changed in the past 20 years. Various endourological treatment modalities, such as extracorporeal shock wave lithotripsy (ESWL), laparoscopic ureterolithotomy and percutaneous nephrolithotomy, are available. Ureteroscopy, as an ideal approach for a series of diagnostic and therapeutic mea- sures, is effective in ureteral surgeries. ${ }^{1,2}$ Since ureteroscopic lithotripsy was first introduced in $1983,{ }^{3}$ it has become the preferred treatment modality for managing ureter stones, as it achieves a high stone-free state in patients.

However, during the lithotripsy, one of the major problems has been movement and retrograde migration of the stones and fragments. The American Urological Association and the European Association of Urology guideline reports that the stone-free rate for ureteroscopy when treating proximal ureteral stones is $81 \%$. The stone-free rate for stones $>10 \mathrm{~mm}$ decreased to $79 \%{ }^{4}$ This situation may need additional procedures involving extraction with retrieval devices, ureterorenoscopy with further fragmentation, or secondary procedures, such as shock wave lithotripsy and ureteroscopy. ${ }^{5,6}$ In addition, residual stone fragments may serve as a source of recurrent stone growth, persistent infection and renal colic. ${ }^{7}$ The difficulty is heightened with the use of a rigid ureteroscope, which cannot access the intrarenal collecting system. To handle this problem, various stone-trapping strategies, such as stone cone, N-trap, and lubricating lidocaine jelly, have been used to prevent stone migration. We describe our experience and evaluate the effectiveness of simultaneous saline irrigation during retrograde rigid ureteroscopic lasertripsy in treating patients with upper-mid ureteral stones.

\section{Methods}

\section{Patients}

From January 2009 to September 2011, 78 patients with 95 ureteral stones were treated at our institution with ureteroscopic lithotripsy using the holmium:YAG laser. We excluded patients who had an active urinary tract infection, a coexisting kidney stone, congenital anomalies, and failure to apply ureteroscopy.

Patients included in our study were randomly divided into two groups for statistical analysis, with each group containing 39 patients. The randomization list was concealed from 
the investigators during this study to avoid selection bias. Patients who underwent conventional ureteroscopic lasertripsy were assigned to Group 1 and patients who underwent ureteroscopic lasertripsy with the use of simultaneous saline irrigation method were assigned to Group 2. The mean age of patients was 48.1 year (range: $26-80$ ). Plain x-ray film of the kidneys, ureters and bladder (KUB), intravenous pyelogram (IVP) or spiral computed tomography (CT) was taken to confirm the diagnosis and determine the exact locations and sizes of the stones. All patients had ipsilateral ureteral stones. In total, 58 patients $(74.3 \%)$ had a single calculus, and the other 20 patients $(25.6 \%)$ had more than 1 . Stone

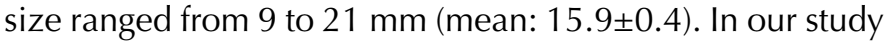
population, 46 cases consisted of stones located above the pelvic brim (upper), 32 cases consisted of stones located over the pelvic brim (mid). They all presented different degree hydronephrosis due to the presence of stones. We documented patient characteristics (Table 1).

In all patients, routine biochemical analysis, blood count, urine culture and urinalysis were performed preoperatively. Prophylactic antibiotics were injected intravenously in all patients preoperatively. No patients had been stented before undergoing ureteroscopy.

\section{Procedures}

Ureteroscopy was performed using the $8 / 9.8 \mathrm{~F}$ rigid ureteroscope (Wolf, Germany), the holmium:YAG laser (Lumenis, China) was used as a lithotripter. The $400 \mu \mathrm{m}$ end-firing fibre was used in all cases; the laser frequency was generally set at $5 \mathrm{~Hz}$ and the energy pulse at $1 \mathrm{~J}$ to minimize risk of ureteric injury.

The operation was performed with patients under spinal anesthesia in the lithotomy position. The introduction of the ureteroscope into the ureter was aided by a 0.038 inch floppy-tipped guidewire without ureteral dilation. In Group 1 , once the stone was visually identified in the ureter, the fibre was introduced via the ureteroscope and the stone was fragmented; fragmented stones were removed from the ureter as much as possible by using a forceps. In Group 2 , once the stone was visually identified, a $4 \mathrm{Fr}$ ureteral catheter (Cook Urological Incorporated, Spencer, IN) was advanced through the ureteroscope until it reached beyond the stone; the ureteroscope was reintroduced again into the ureter beside the ureteral catheter and advanced to the level of the stone. The end of the catheter connected to a saline irrigate bag and the saline was injected through the catheter continuously and accelerated with squeezing pump as needed during the operation. The laser fibre was advanced through the ureteroscope and applied near the stone under direct vision where it was fired and the process was continued until the stone was completely fragmented. At this time, saline with perfusion through the catheter filled the pelvis and washed out any particles between the stone and the catheter; this allowed a clear lithotripsy with no risk of displacing the stone. Moreover, minute stone fragments were also washed out (downward washout) with saline irrigation, and helped dissipate the heat generated by the absorption of laser energy during stone fragmentation.

After complete fragmentation of the stone, the laser fibre was removed from the working channel. A double J stent was placed postoperatively in all patients. The procedure was considered successful in both groups if no proximal stone migration occurred, if the stone was fragmented completely (into 2 to 3 particles), and if the calculus subsequently cleared on follow-up radiographs.

Postoperative KUB was performed the next morning (24 hours after the operation) to examine migration and residual

\section{Table 1. Preoperative criteria in both groups}

\begin{tabular}{|c|c|c|c|}
\hline & Group I & Group II & Total \\
\hline No. cases & 39 & 39 & 78 \\
\hline Men & 21 & 26 & 47 \\
\hline Women & 18 & 13 & 31 \\
\hline Age (yr) & $45.2 \pm 13.8$ & $43.7 \pm 14.6$ & 48.1 \\
\hline \multicolumn{4}{|l|}{ Site of stone } \\
\hline Proximal ureter & $21(27 \%)$ & $25(32 \%)$ & $46(59 \%)$ \\
\hline Mid ureter & $18(23 \%)$ & $14(18 \%)$ & $32(41 \%)$ \\
\hline \multicolumn{4}{|l|}{ Stone size } \\
\hline Proximal ureter & $\begin{array}{c}\text { Range: } 8-20 \\
\text { Mean } \pm \text { SD } 14.0 \pm 0.1\end{array}$ & $\begin{array}{c}\text { Range: } 9-18 \\
\text { Mean } \pm \text { SD } 13.2 \pm 0.3\end{array}$ & \\
\hline Mid ureter & $\begin{array}{c}\text { Range: } 9-18 \\
\text { Mean } \pm \text { SD } 13.0 \pm 0.3\end{array}$ & $\begin{array}{c}\text { Range: } 8-21 \\
\text { Mean } \pm \text { SD } 14.3 \pm 0.7\end{array}$ & \\
\hline \multicolumn{4}{|l|}{ State of kidney } \\
\hline Mild hydronephrosis & $5(6 \%)$ & $7(9 \%)$ & $12(15 \%)$ \\
\hline Moderate hydronephrosis & $22(28 \%)$ & $19(24 \%)$ & $41(52 \%)$ \\
\hline Severe hydronephrosis & $12(15 \%)$ & $13(17 \%)$ & $25(32 \%)$ \\
\hline
\end{tabular}


stone fragments. All cases of migration were treated with adjunctive ESWL. Patients were discharged and returned after 1 month for follow-up KUB or spiral CT scan, and for removal of the double $\mathrm{J}$ stent.

\section{Statistical analysis}

Statistical analysis was performed with the SPSS v.12.0 (SPSS Inc, Chicago, IL) by using of mean \pm standard deviation, chisquare test and Fisher 2 -sided exact test. A $p<0.05$ was considered statistically significant.

\section{Results}

The holmium:YAG laser successfully fragmented all calculus into small fragments. The rates of upward stone migration were $20 \%$ and $2 \%$ for Group 1 and Group 2, respectively. Group 2 showed a significantly higher success rate than Group 1. In total, 9 patients failed with this treatment and were treated with one ancillary procedure (SWL) after 1 week. The operative time in Group 1 ranged from 35 to

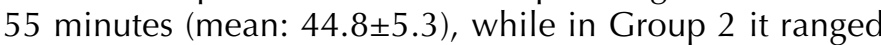
from 40 to 69 minutes (mean: $50.4 \pm 3$ ), respectively. The average time to properly place the irrigation catheter above the stone was 8 minutes. No stones had been pushed into the kidney by the catheter. Although Group 1 showed a shorter mean duration than Group 2, the difference was not statistically significant.

Follow-up after 1 month by KUB or spiral CT scan showed complete stone clearance in all Group 2 patients. In Group 1, complete clearance occurred in 36 patients; 3 patients had 2 or 3 clinically insignificant residual fragments smaller than $3 \mathrm{~mm}$, and no patient had clinically significant residual fragment in both groups. Postoperative low grade fever occurred in 9 patients in Group 1 and 2 in Group 2; mucosal tearing, ureteral perforation, urinoma and urosepsis were not seen in both groups. No long-term complications were found. Hospital stay ranged from 1 to 4 days (mean: $1.8 \pm 0.4)$.

We analyzed data on upward stone or fragment migration, lengths of time and stone clearance in both groups (Table 2).

\section{Discussion}

Ureteroscopic lithotripsy has emerged as the most expeditious and cost-effective way to treat ureteral calculi. ${ }^{8}$ Stones that are too large to be removed intact must be fragmented first. Many clinical studies confirm the efficacy of the holmium:YAG laser in fragmenting calculi of any composition. ${ }^{9,10}$ However, during ureteroscopic lasertripsy, proximal migration remains a significant problem in managing stones that are located in the mid or upper ureter, where the stone is more likely to move to the intrarenal collecting system; this is especially problematic in hospitals in which rigid ureteroscopes, not flexible endoscopes, are only available. Devarajan and colleagues report only a $77 \%$ success rate for upper ureteric calculi during ureteroscopic holmium:YAG laser lithotripsy. ${ }^{11} \mathrm{Knispel}$ and colleagues report an incidence rate of $40 \%$ to $50 \%$ for ureteral calculus migration from the proximal ureter and $5 \%$ to $10 \%$ from the distal ureter. ${ }^{12}$ Gupta reports a 3.3\% failure rate due to retropulsion using Holmium laser. ${ }^{13}$ The risk of proximal fragment migration is influenced by the pressure of irrigate fluid, type of energy source used for intracorporeal lithotripsy, site and degree of calculus impaction, and greater proximal ureteral dilation or hydronephrosis. ${ }^{14,15}$ Additional procedures, such as ESWL, might be required to treat residual migrated fragments. ${ }^{16,17}$

To prevent stone migration, surgeons have traditionally used a number of maneuvers, including reverse Trendelenburg position, to optimize the effects of gravity and to decrease irrigation pressure and flow rate. These techniques, however, compromise surgeon comfort and visibility and can also prolong procedures. ${ }^{12,18} \mathrm{~A}$ variety of devices have also been designed to minimize stone retropulsion and increase ureteroscopic efficiency. These devices, including the use of ureteral baskets, lithocatch, passport balloon, parachute, entrapment net (N Trap), accordion, backstop and the stone cone have resulted in stone-free rates greater than $95 \%$ with low morbidity. ${ }^{19}$

In this study, since we do not have access to flexible ureteroscopes, we used the rigid ureteroscope and simultaneous saline irrigation method to treat upper-mid ureteral stones with good results. Its advantages are as follows: (1) ureteroscope can be easily reintroduced into the ureter through catheter guide; (2) the catheter stuck next to the stone, and made upward migration difficult during lasertripsy; and (3) with the catheter irrigation, proximal stone fragments migration was obstructed by the downward washout during lasertripsy, creating a flush of stone fragments into the distal ureter or bladder. Similarly, this flushing effect can also improve visibility, rendering lasertripsy more accurate and efficient.

The difference was in favour of Group 2 which showed few stone migrations and higher stone-free rates; these differences were significant $(p<0.05)$. The mean operative times between our two groups were not statistically significant.

\begin{tabular}{lcc}
\hline $\begin{array}{l}\text { Table 2. Upward stone migration, operative time and stone } \\
\text { clearance in both groups }\end{array}$ & Group I & Group II \\
\hline & $8 / 39(20 \%)$ & $1 / 39(2 \%)$ \\
\hline Number of stone migrations & $44.8 \pm 5.3$ & $50.4 \pm 3$ \\
Operative time (min) & $36 / 39(92 \%)$ & $39 / 39(100 \%)$ \\
Stone clearance (after 1 month)
\end{tabular}

There was significant difference between both groups as regards proximal stone migrations and stone clearance $(p<0.05)$. 
This favours the paracalculous ureteral catheter continuous antegrade perfusion method as an efficient device to prevent stone migration. Moreover, it does not add to the cost of the procedure in contrast to the conventional ureteroscopic lasertripsy.

Several operative pitfalls should be taken into consideration. The laser lithotripsy should begin at the lowest power setting as this gives a feel for the stone and the rate of fragmentation. We usually set the frequency at $5 \mathrm{~Hz}$ and the energy pulse at $1 \mathrm{~J}$; we found that this power setting can fragment the stone with maximum efficiency, with the least likelihood that the stone would be propelled back into the kidney. Another consideration is the potential for infection after the operation. Bacteriuria is common in patients with large stones subjected to lithotripsy; the bacteria can be released from the infected stones as they disintegrate. To cope with this, broad-spectrum antibiotics are given preoperatively and postoperatively. During the operation, once the ureteral catheter reached beyond the stone, the purulent urine flowed downward and we found pyonephrosis, we usually removed ureteroscope and left the ureteral catheter drainage for several days until the inflammation was controlled; in these cases, we re-operated. In our study, lowgrade fever occurred postoperatively in 9 patients in Group 1 and 2 patients in Group 2; there was no high-grade fever.

\section{Conclusion}

We found that during ureteroscopic lasertripsy, using the simultaneous saline irrigation method overcame the drawbacks of poor visibility and poor flushing compared to traditional methods; it also minimized the risk of stone migration and allowed us to safely remove the stone. It did not add to the cost of the procedure and is particularly suitable in hospitals with no access to flexible ureteroscopes. More clinical studies to assess patient benefits are needed.

Competing interests: None declared.

This paper has been peer-reviewed.

\section{References}

1. Su LM, Sosa RE. Ureteroscopy and retrograde ureteral access. In: Walsh PC, Retik AB, Vaughan ED, Wein AJ, ed. Campbell's Urology, $8^{\text {th }}$ edition. Philadelphia, PA: WB Saunders; 2002:3306-18.

2. Camilleri JC, Schwalb DM, Eshghi M. Bilateral same session ureteroscopy. J Urol 1994;152:49-52.

3. Huffman JL, Bagley DH, Schoenberg HW, et al. Transurethral removal of large ureteral and renal pelvic calculi using ureteroscopic ultrasonic lithotripsy. J Urol 1983;130:31-4.

4. AUA/EAU clinical guidelines. 2007. http://www.auanet.org/content/guidelines-and-quality-care/clinicalguidelines/main-reports/uretcal07/chapterl.pdf. Accessed February 1, 2013.

5. Chow GK, Blute ML, Patterson DE. Ureteroscopy: update on current practice and long term complications. J Urol 2001;165:71.

6. Delvecchio FC, Kuo RL, Preminger GM. Clinical efficacy of combined Lithoclast and Lithovac stone removal during ureteroscopy. J Urol 2000;164:40-2. hitp://dx.doi.org/10.1016/S0022-5347(05)67444-7

7. Delvecchio FC, Preminger GM. Management of residual stones. Urol Clin N Am 2000;27:347-54. http:// dx.doi.org/10.1016/S0094-0143(05)70263-9

8. Grasso $M$, Beaghler $M$, Loisides $P$. The case for primary endoscopic management of upper urinary tract calculi: Il. Cost and outcome assessment of 112 primary ureteral calculi. Urology 1995;45:372-6. http:// dx.doi.org/10.1016/S0090-4295(99)80003-X

9. Watson GM, Smith N. A comparison of the pulsed dye and holmium lasers for stone fragmentation: in vitro studies and clinical experience. SPIE Vol. 1879 Lasers in Urology, Gynaecology and General Surgery 1993:139-42.

10. Matsuoka K, lida S, Nakanami M, et al. Holmium Yttrium-Aluminum-Garnet Laser for endoscopic lithotripsy. Urology 1995;45:947-52. http://dx.doi.org/10.1016/S0090-4295(99)80113-7

11. Devarajan $R$, Ashraf $M$, Beck RO, et al. Holmium: YAG lasertripsy for ureteric calculi: an experience of 300 procedures Br J Urol 1998;82:342-7. http://dx.doi.org/10.1046/i.1464-410X.1998.00754.x

12. Knispel HH, Klän R, Heicappell R, et al. Pneumatic lithotripsy applied through deflected working channel of miniureteroscope: results in 143 patients. J Endourol 1998;12:513-5. http://dx.doi.org/10.1089/ end.1998.12.513

13. Gupta PK. Is the holmium: YAG laser the best intracorporeal lithotripter for the ureter? A 3-year retrospective study. J Endourol 2007;21:305-9. http://dx.doi.org/10.1089/end.2006.0247

14. Hendlin K, Weiland D, Monga M. Impact of irrigation systems on stone migration. J Endourol 2008;22:4538. http://dx.doi.org/10.1089/end.2007.0260

15. Lee H, Ryan RT, Teichman JM, et al. Stone retropulsion during holmium:YAG lithotripsy. J Urol 2003;169:881-5. http://dx.doi.org/10.1097/01.ju.0000046367.49923.c6

16. Singal RK, Denstedt JD. Contemporary management of ureteral stones. Urol Clin North Am 1997;24:59-70. http://dx.doi.org/10.1016/S0094-0143(05)70354-2

17. Sun $Y$, Wang $L$, Liao $G$, et al. Pneumatic lithotripsy versus laser lithotripsy in the endoscopic treatment of ureteral calculi. J Endourol 2001;15:587-90. http://dx.doi.org/10.1089/089277901750426346

18. Mirabile G, Phillips CK, Edelstein A, et al. Evaluation of a novel temperature-sensitive polymer for temporary ureteral occlusion. J Endourol 2008;22:2357-9. http://dx.doi.org/10.1089/end.2008.0029

19. Gameel T, Radwan M, Ramadan A, et al. A comparison of Stone Cone versus lidocaine jelly in the prevention of ureteral stone migration during ureteroscopic lithotripsy. Ther Adv Urol 201 1;3:203-10. http:// dx.doi.org/10.1177/1756287211419551

Correspondence: Dr. Lu Sun, Department of Urology, The People's Hospital of Yichun, Yichun, Jiang Xi 336000, China; bigrabbit99@126.com 